\title{
Experimental Investigation of Water Droplet Phase Change in Humidified Air Flow
}

\author{
Virginijus RAMANAUSKAS*, Linas PAUKŠTAITIS**, Gintautas MILIAUSKAS***, \\ Egidijus PUIDA***** \\ *JSC “Enerstena”, Ateities pl. 30 a, LT-52317 Kaunas, Lithuania, E-mail: Virginijus.Ramanauskas@enerstena.lt \\ **Kaunas University of Technology, Studentu 56, Kaunas, LT-51424, Lithuania, E-mail: linas.paukstaitis@ktu.lt \\ ***Kaunas University of Technology, Studentu 56, Kaunas, LT-51424, Lithuania, E-mail: gintautas.miliauskas@ktu.lt \\ ***Kaunas University of Technology, Studenty 56, Kaunas, LT-51424, Lithuania, E-mail: egidijus.puida@ktu.lt

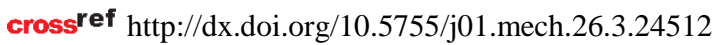

\section{Introduction}

In industry, energy, transport [1-9] and others many technologies are based on heat and mass transfer processes of sprayed water. The applicability of the sprayed liquid is very diverse. However, at the surface of the droplets the phase transient process is important, because its rate ensures the efficiency of the technologies. Liquid fuels and water are often used in practice. In liquid fuel technology, it is desirable for the droplets to evaporate as quickly as possible, since it is not the liquid fuel that burns, but its vapour. Into the combustion zone the liquid fuel vapour through a diffusive layer surrounding each droplet is supplied. In water spray technology, a condensation phase transient mode is important. Therefore, the phase transient mode of the sprayed liquid droplets can generally consist of sequentially changing condensation, transient evaporation, and equilibrium evaporation regimes. They all are very important in modern biofuel combustion technologies [10].

The driving force $F_{f}$ of the phase transition on the surface of the liquid is defined by the difference $\Delta p_{f}$ of the partial pressure of the vapour in the diffuse layer:

$$
F_{f}(\tau) \equiv \Delta p_{f}(\tau)=p_{v, H}(\tau)-p_{v, \delta_{D}}(\tau),
$$

where: $p_{v, H}$ and $p_{v, \delta_{D}}$ are the partial vapour pressure of the liquid in the gas mixture at the liquid surface $H$ and at the outer perimeter of the diffuse layer, respectively, $\mathrm{Pa} ; \delta_{D}$ is the thickness of the diffuse layer, $\mathrm{m}$; $\tau$ is the time of the phase transition process, $\mathrm{s}$.

When the partial pressure of the vapour $p_{v, H}$ is greater than the pressure $p_{v, \delta_{D}}$, a superficial evaporation of the liquid takes place and the vapour of the liquid diffuses through the diffusion layer into the liquid gas. In case of $p_{v, H}<p_{v, \delta_{D}}$, the liquid vapour diffuses through the diffusion layer towards the liquid in the humid gas mixture. The condensation process requires the $T_{H}$ surface temperature of the liquid to be below the dew point $T_{d p}$. The liquid vapour is then cooled to the saturated temperature and condensed.

Thus, the mode of phase transition on the surface of the dispersed liquid is closely related to the thermal state of the droplets. The latter is defined by the instantaneous equilibrium of the heat fluxes supplied to the liquid and the heating and evaporating fluxes of the liquid. This is generally described as the volume of the liquid in formal terms:

$$
\vec{q}_{\Sigma, H^{+}}(\tau)+\vec{q}_{\Sigma, H^{-}}(\tau)+\vec{q}_{f, H^{+}}(\tau) \equiv 0
$$

where: $q_{\Sigma, H^{+}}$is the total heat flow to the liquid volume from the external heat source, $\mathrm{W} / \mathrm{m}^{2} ; q_{\Sigma, H^{-}}$is the total heat flow introduced into the fluid volume by the internal heat transfer, $\mathrm{W} / \mathrm{m}^{2} ; q_{f, H^{+}}$is the heat of phase transition released in the steam condensation process or used to vaporize the liquid, $\mathrm{W} / \mathrm{m}^{2}$.

The latter is described as the vapour flux $\left(g_{v}, \mathrm{~kg} / \mathrm{s}\right)$ density $\left(m_{v} \mathrm{~kg} /\left(\mathrm{m}^{2} \mathrm{~s}\right)\right)$ and the heat of the liquid phase transitions $(L, \mathrm{~J} / \mathrm{kg})$ :

$$
q_{f, H^{+}}(\tau)=m_{v}(\tau) L(\tau)=\frac{g_{v}(\tau)}{A_{H}(\tau)} L(\tau)
$$

where: $A_{H}$ is the surface area of the liquid volume, $\mathrm{m}^{2}$. The surface area of the liquid volume changes due to the expansion of the warming fluid and the phase transition on its surface.

The parameter $\bar{g}_{l}=G_{l} / G_{g}$ expressed as the ratio of the flow rate of the injected liquid to the gas is important for defining the biphasic flow of liquid micro-volumes and gas. The resulting liquid volumes are grouped into the number of selected groups $I$ and the proportion of the relative flow rate of the liquid to be dispersed for each group $i$ is estimated. The fluid volume sphericity assumption is often applied. The equivalent droplet diameter of $2 R_{e k v, i}$, for each group is defined. The area $A_{H}$ of the liquid surface (3) is then equated to the $A_{R}$ area of the equivalent sphere, which for each group of droplets is individual:

$$
A_{R, i}=4 \pi R_{e k v, i}^{2} ; \quad R_{e k v, i}=\frac{3}{4 \pi} \frac{M_{R, i}}{\rho_{l}} ; M_{R, i}=\frac{M_{l, l}}{N_{i}},
$$

where: $A_{R, i}$ is the surface area of the equivalent droplet of group $i, \mathrm{~m}^{2} ; M_{R, i}$ is the mass of equivalent droplet in group $i, \mathrm{~kg} ; M_{l, i}$ is the mass of the liquid in the group of droplets $i, \mathrm{~kg} ; N_{i}$ is the number of droplets connected to group $i$.

In defining the function $g_{v}(\tau)$ of vapour flow for liquid spray technology it is necessary to specify the formal (1-3) model. For this, certain assumptions are made and empirical correlations describing the various transfer processes 
are applied. Therefore, in practice different theoretical models are used for droplet heat and mass transfer investigation and various methods of their solution are applied [11-15]. When modelling phase transition in a two phase flow, particular boundary conditions of the droplet transfer processes need to be considered. The parameters of the gas flow and the dispersible liquid are important. Since the rate of the transfer processes in the droplet groups of different dispersion is different, the solution results of the equations system will be individual for every droplet groups (1-4).

The reliability of the modelling results must be based on the experimental results. Therefore, the experimental researches results of the liquid droplets heat and mass transfers are important both for the definition of transfer processes regularities and for the reliability evaluation in modelling methodology. The liquid droplets evaporation process was well experimentally investigated.

The primary experimental results for droplets evaporation in low-temperature air was summarized in work [16]. Further experiments had shown that, for water [10, 1733] et. all., for fuels and other liquids [34-47] the evaporation of a droplets takes place in a wide range of boundary conditions when taking into account the influence of environmental characteristics and the heat transfer boundary conditions of the droplets. Pure fuel [39], diesel and biodiesel [42, 43], kerosene [44-46], various oils [37, 38], fuel mixtures [35, 41], and other multi-component fuel droplets $[34,47]$ are popular subjects of experimental and theoretical studies of the fuel droplets.

The heat and mass transfers processes of a water droplets have been experimentally investigated in different boundary conditions: while evaporation in the gas flows [17-21], in contact with surfaces [22, 23], in icing nucleation [24] and crystallization [25], in the freezing of a cold surface [26-29], and in various emulsions [30-32]. The research of heating and evaporation of a water droplet overflown by air flow is presented in the work [21]. This work is distinguished by the complexity of experimental research and numerical modelling in a wide range of air temperature variations from 100 to $800^{\circ} \mathrm{C}$. Various measurement methods have been used that are calibrated with each other in the study [21]. It is interesting to note that not only the change in the average temperature of the evaporating water droplet is investigated, but also warmth of the droplet layers is experimentally determined. The results suggest that the temperature of the droplet is non-homogeneous during the heating process, and the influence of water circulation on the temperature field gradient in the droplet is defined by the effective thermal conductivity coefficient according to the [48] model.

An experimentally investigated the droplets evaporation in a radiative medium is difficult. In work [33], exceptionally original experiments for water droplet equilibrium evaporation were carried out while heating the droplet by complex heat transfer of radiation and weak forced convection. The results of these studies were used for validation of the complex heat transfers and numerical models of the evaporation water droplets $[49,50]$.

The definition universality of liquid droplets heat and mass transfer modelling and experimental research results is improved by their analysis in universal time scale expressed by Fourier number. It is defined by the calculated number $F o \equiv \tau \cdot a_{0} / R_{0}^{2}$ for the initial conditions of the droplet [50]. For the current practise of research results processing, it is popular to use the time scale $\tau_{\text {mod }} \equiv \tau / R_{0}^{2}, \mathrm{~s} / \mathrm{mm}^{2}$ which is proportional for the droplet initial surface area, in order to eliminate the influence of initial temperature of liquid [35-38, 40, 43, 46]. The modified time scale $\bar{\tau}_{\text {mod }} \equiv \tau \cdot D_{v, 0} /\left(2 R_{0}\right)^{2}$ cases in the aspect of diffusion coefficient are also available [39].

The applicability and specificity of water spraying in biofuel combustion technologies and the importance of cognition of droplet phase transitions have been extensively discussed [10]. Two characteristic cases of water injection into biofuel flue gas can be distinguished. In the first case, the water, together with the dissolved detergents, is injected into the flue gas at $800-1000^{\circ} \mathrm{C}$ to reduce the concentration of toxins. In the second case, water is injected into the flue gas at $150-200^{\circ} \mathrm{C}$ to improve the heat recovery process. In the first case, experimenting with high temperature flue gas is difficult. Therefore, for the verification of modelling results of heat and mass transfer of the sprayed liquid the experimental investigation of the water droplet thermal state and transfer processes is important in relatively low-temperature flue gas. In the experiments, flue gas is often treated as a mixture of dry air and water vapour. Relative humidity of air is an important factor [10, 51, 52]. In the air, at a higher relative humidity the water droplets may even cool in a transient evaporation mode $[10,51]$. The moisture content of biofuel flue gas, expressed as a volume fraction of water vapour, can be very high and exceed 0.3 . For the removed biofuel flue gas, an experimental investigation of water droplets thermal state in additionally humidified and heated air flow was performed for near real conditions [10]. Its results highlighted not only the quantitative but also the qualitative effect of air humidification and initial water temperature on the thermal state of the droplets.

In this work results of experimental research on the phase change of water droplets in additionally humidified air flow were presented and analysed. Impact of air heating and additional humidification for droplet diameter change was estimated.

\section{Experiment method and processing of the results}

The principal scheme of the experimental setup was presented and described in detail in the work [10]. A droplet of water is pipetted onto the thermocouple bead. With a special injection system, the droplet is placed in the centre of a $5 \times 5 \mathrm{~cm}$ square experimental channel where it is overflown with air. The airflow settings can be changed by heating the room air in the heater and adding vapour from the water vaporizer and adjusting the blower capacity. The thermodynamic parameter of environment air is measured using a TESTO 445 device. The water droplet changes of temperature $t_{l},{ }^{\circ} \mathrm{C}$ is recorded with $\mathrm{K}$ type thermocouple. According to droplet temperature measuring results the thermogram $t_{l}(\tau)$ is formed. The temperature of air stream $t_{g},{ }^{\circ} \mathrm{C}$ is defined by the stabilized temperature of the thermocouple bead after the water has been evaporated. The humidity of the air stream flow is calculated from the air flow rate and the water vapour component of the air stream: 


$$
\bar{g}_{v, g}=\frac{G_{v}}{G_{g}}
$$

where: $\bar{g}_{v, g}$ is the mass fraction of water vapour in the air; $G_{v}$ is the water vapour flow rate, $\mathrm{kg} / \mathrm{s} ; G_{g}$ is the air flow rate, $\mathrm{kg} / \mathrm{s}$.

The airflow and the water vapour component in the experimental section are defined according to working model (1-7) [10]. The hydrodynamics regime of gas flow is determined by Reynolds $R e_{g}$ number:

$$
R e_{g}=\frac{G_{g}}{\rho_{g} v_{g} l_{k}} \text {. }
$$

The hydrodynamics regime of droplet overflow is determined by Reynolds $R e_{l}$ number:

$$
R e_{l}=2 \frac{G_{g} R}{\rho_{g} v_{g} l_{k}^{2}},
$$

where: $\rho_{g}$ is air density, $\mathrm{kg} / \mathrm{m}^{3} ; v_{g}$ is kinematic viscosity of air, $\mathrm{m}^{2} / \mathrm{s} ; l_{k}$ is the characteristic dimension of the experimental channel, $\mathrm{m} ; 2 R$ is the diameter of the equivalent sphere of the thermocouple bead and the surrounding water system, m.

Due to the phase transitions on the surface of the water and the expansion of the warming water the equivalent diameter of the droplet changes. The droplet is illuminated through the glass wall of the channel and its projection is increased by approximately 30 times (Fig. 1).

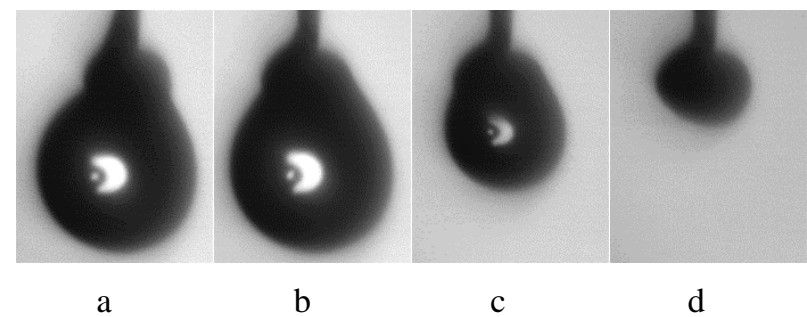

Fig. 1 Water droplet in different times: a) the beginning of the experiment, b) the maximum diameter of a droplet, c) the evaporation process, and d) only the thermocouple is visible

Fig. 1 shows the variation of water droplet diameter in humid air flow in different time moments. Image a) shows a water droplet at the beginning of the experiment in a humid air flow. In image b), the water droplet reaches its maximum diameter due to water thermal expansion and vapour condensation. Image c) shows the water droplet in to evaporation process. Finally, image d) is taken at the end of the experiment where only the thermocouple bead is visible.

A graph of the droplet equivalent diameter change function $2 R(\tau)$ is created/drawn in a basis of image recognition methodology [53]. The methodology used for the video frame processing is shown in Fig. 2. In Fig. 2, the presented droplet was enlarged by approximately 33 times. First, the unprocessed image a) is read by the program, and with the help of Gaussian filter, the image b) is processed in order to minimize errors of the identification limit of grey colour after using a filtering the black and white imagine is get (c); where the white line indicates the edge of water droplet. Using the recovery sub-program, white lines are connected to a solid line which marks the perimeter (d) of the water droplet. The image is inverted from black to white, and the water droplet is filled with a black colour (e). The area filled with the black colour is calculated, and converted into the equivalent diameter of a water droplet.

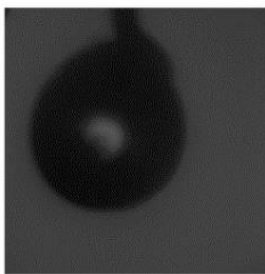

a

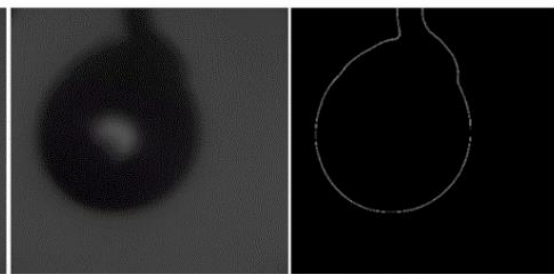

$\mathrm{b}$

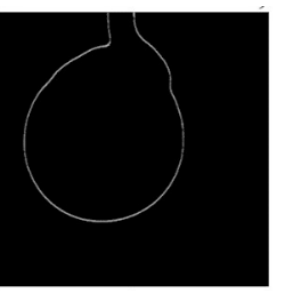

d

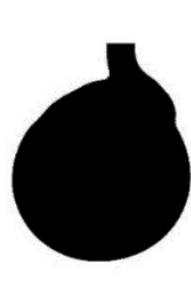

Fig. 2 Main principle of created program for image recognition and analysis in MATLAB environment

\section{Experimental results and discussion}

The experiment was performed for the regularities definition of water droplets phase change in biofuel flue gas flow. In the experimental investigations the biofuel flue gas is replaced by heated and additionally humidified air flow. By heating and additionally humidifying air flow, was focused on the water droplets heat and mass transfer processes boundary conditions, which are specific for condensing economisers for heat recovered of the removed biofuel flue gases, when flue gas average temperature $t_{g}=80 \div 100^{\circ} \mathrm{C}$ and vapour volume (molar) fraction in gas mixture $\bar{p}_{v, g} \equiv P_{v, g} / P_{g}=0 \div 0.2$.

The phase change regime of a droplet is defined by the water temperature and the air humidity. The water droplet in humid air flow can evaporate or water vapour may condense on it. The influence of the boundary conditions for the droplet heat transfer and phase change is provided in the graphs of the equivalent diameter variation (Fig. 3-5).

The variation diagrams for a droplet and thermocouple bead system of equivalent $2 R$ diameter are created according to the results of a video camera when following the procedure described above. The initial water $t_{l 0}$ temperature and initial equivalent $2 R_{0}$ diameter are fixed just before an air flow contact with the droplet.

The variation of the equivalent diameter of a droplet is determined through two processes. One is the thermal expansion of the heated water, and the second one is the phase changes on the droplet surface. Both of these factors are closely related to the change in the thermal state of the droplet (Fig. 6). In the humid air gas flow the droplets thermal state change and the phase change regimes cycle of a water droplets can be qualitatively defined by dimensionless $\bar{T}_{d p}=T_{d p} / T_{0}$ and $\bar{T}_{e}=T_{e} / T_{0}$ parameters [54]. The dew point $T_{d p}$ temperature is defined by the humidity of the air. 


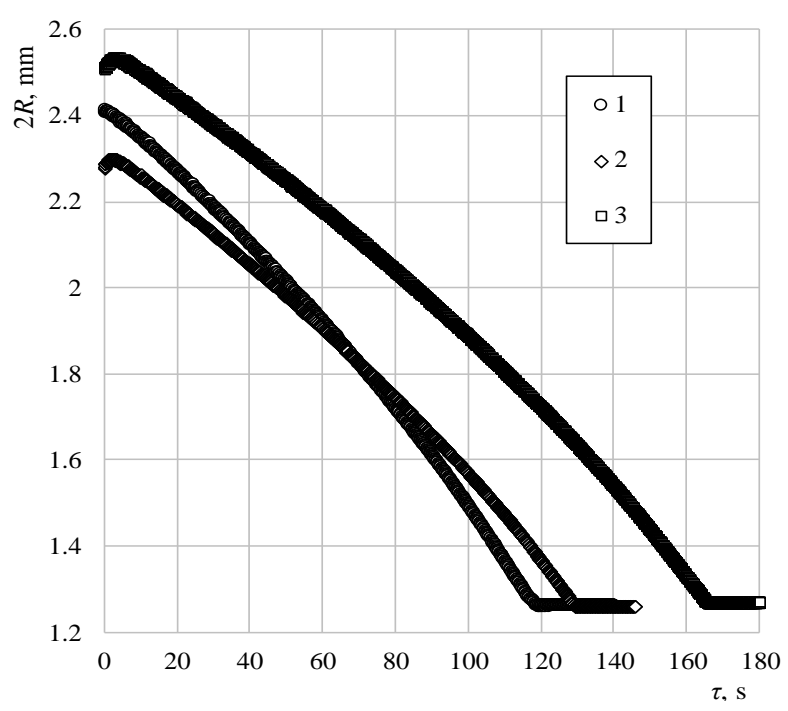

a

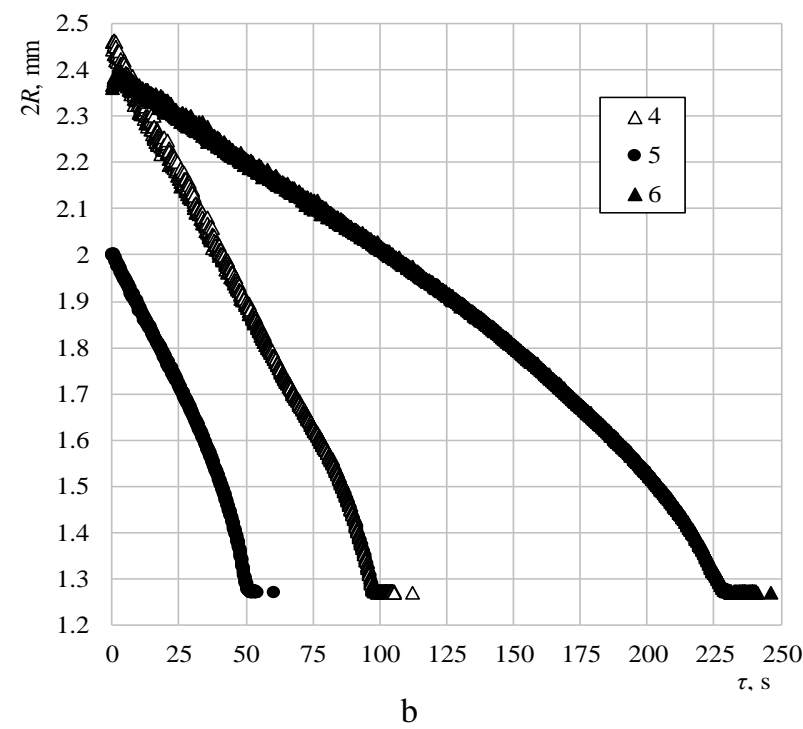

Fig. 3 The variation of water droplet equivalent diameter in phase changes regimes for humid air flows. $t_{d p},{ }^{\circ} \mathrm{C}: 1$ 10.62, $2,330.84,4,54.97,653.23 ; t_{0},{ }^{\circ} \mathrm{C}: 131.7,2$ 30.3, 3 24.7, 4 36.6, 5 33.9, 635 ; $R_{0}$, mm: 1 2.41, 2 2.28, 3 2.51, 4 2.46, 5 2, 6 2.36; $P_{g}$, hPa: 1-3 989, 45 1000.3; $G_{g} \cdot 10^{3},{ }^{\circ} \mathrm{kg} / \mathrm{s}: 19.244,2,39.438,4-515.88$, 6 17.452; Reg: 1 28554.2, 2 8869.4, 3 8877.4, 4, 5 15032.6, 6 17871.9; $\operatorname{Re}_{l}: 1$ 824.6, 2 808.9, 3 891.3, 4 1479.2, 5 1204.4, 6 1687.1; $t_{g},{ }^{\circ} \mathrm{C}: 1$ 96.6, 2 96.5, 3 96.1, 4, 5 85.6, 6 80.9; $\bar{p}_{v, g}: 10.0129,2,30.045,4$,

\section{$50.0087,60.1444$}

At equilibrium evaporation $T_{e}$, the heat supplied to the droplet evaporates the water only. Thus, the temperatures $T_{d p}$ and $T_{e}$ defines the heat and mass transfer boundary conditions of the droplet, and the temperature of the sprayed water $T_{0}$ can be chosen freely. The condition $\bar{T}_{r t}>1$ is necessary for a full phase change cycle, when condensation, transient evaporation and equilibrium evaporation regimes occurs sequentially; otherwise, at condition $\bar{T}_{e}>1$, the droplet warm up to the equilibrium evaporation temperature and evaporate, or will cool down at $\bar{T}_{e}<1$. Theoretical generalisation of parameters $\bar{T}_{r t}$ and $\bar{T}_{r t}$ have been verified and validated experimentally in the paper [10].
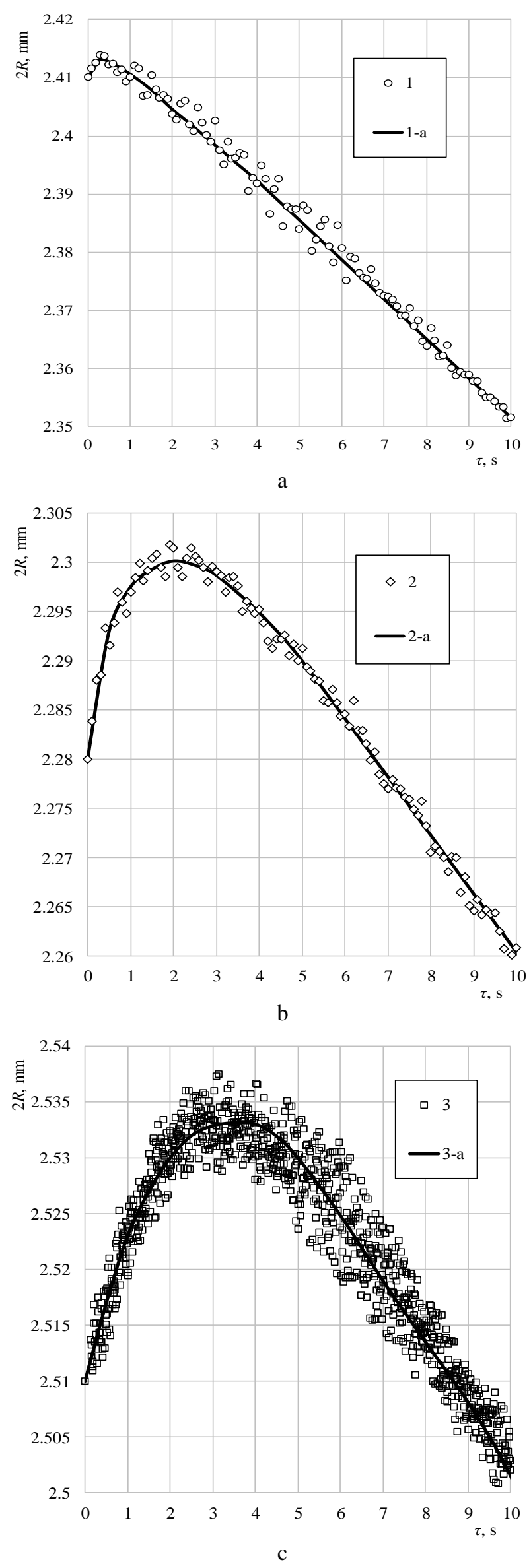

Fig. 4 The influence of initial phase change regime and experimental boundary conditions (1-3) on the variation of droplet equivalent diameter. Case (1-3) are indicated in Fig. 3 


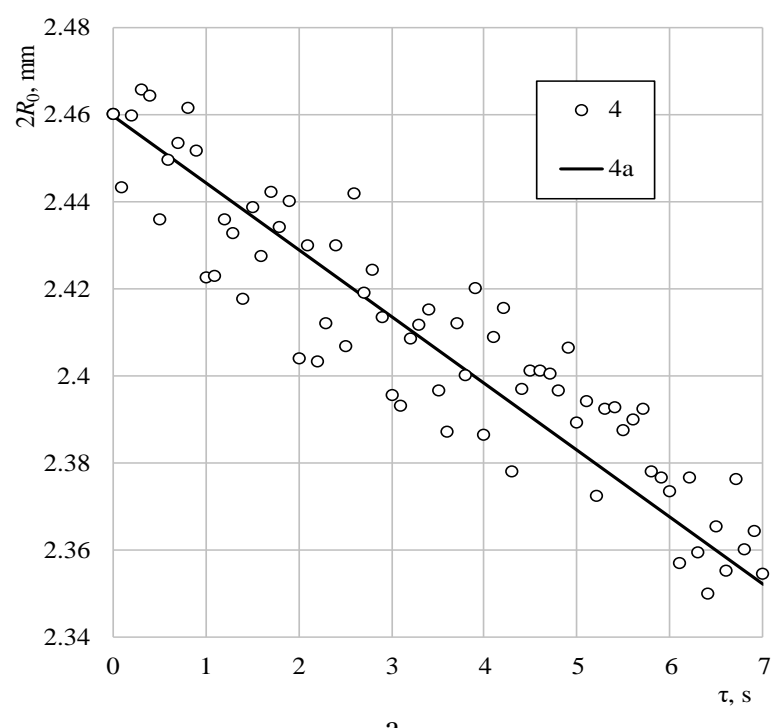

a
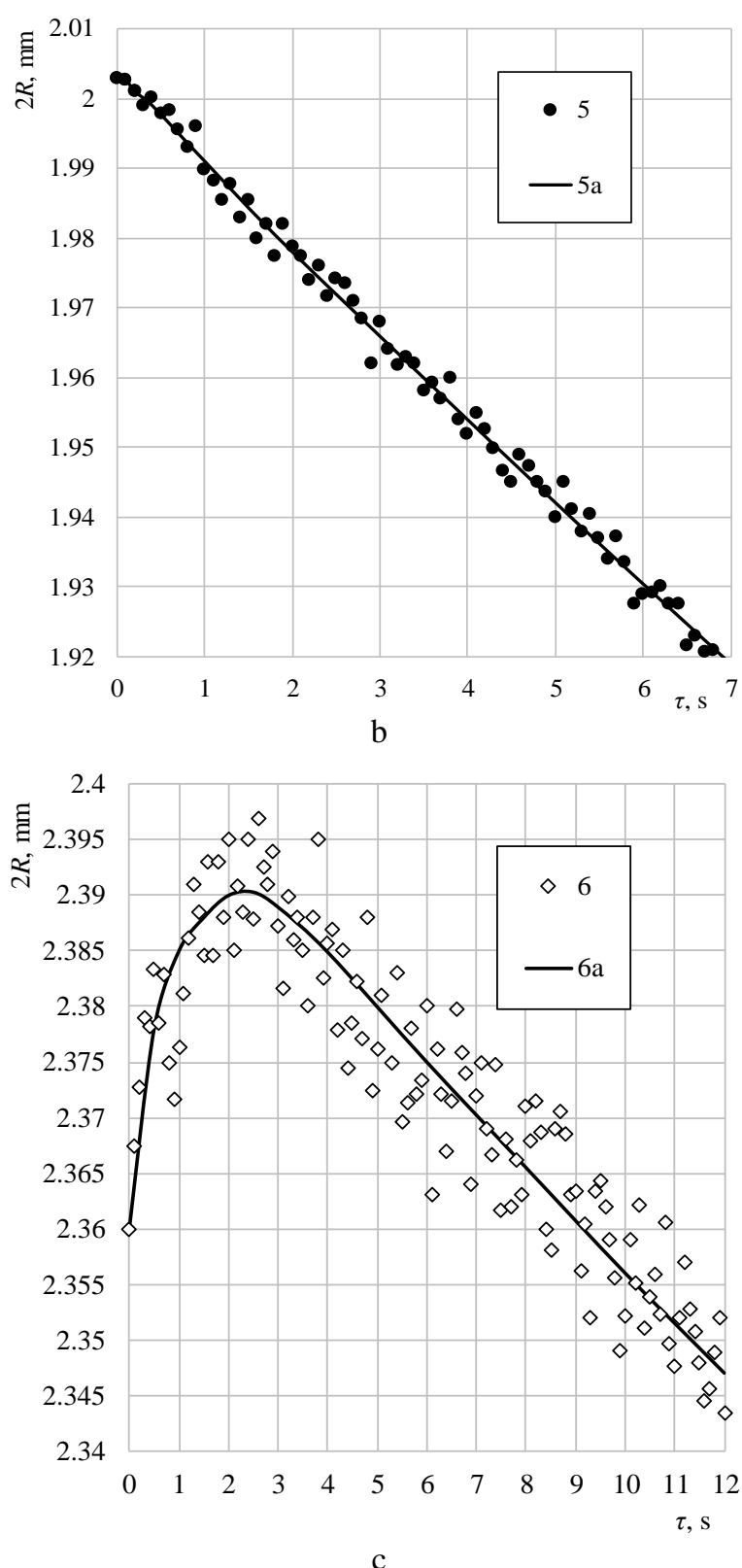

Fig. 5 The influence of initial phase change regime and experimental boundary conditions (4-6) on the variation of droplet equivalent diameter. Case (4-6) are indicated in Fig. 3

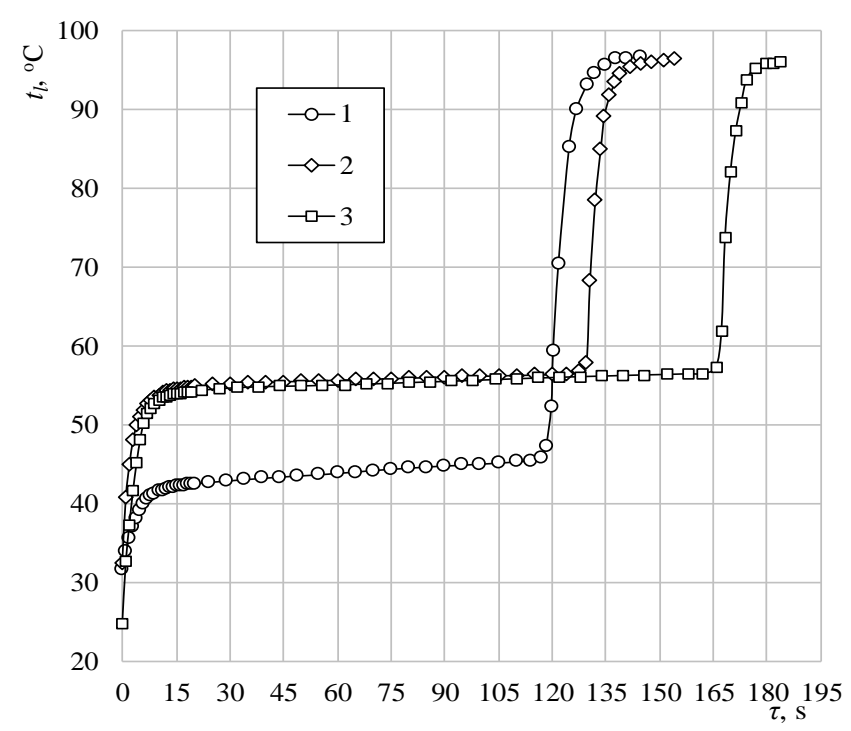

a

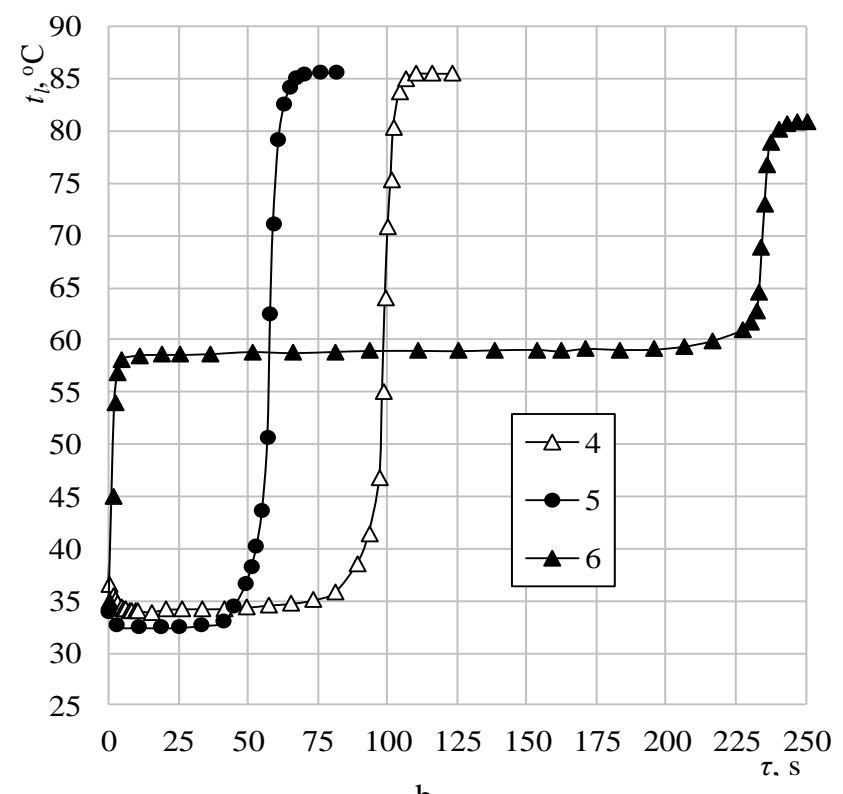

b

Fig. 6 The variation of water droplet temperature in phase changes regimes for humid air flows [10]. Case (1-6) are indicated in Fig. 3

The condition $\bar{T}_{r t}>1$ is satisfied in the second, third, and sixth experiments, which results in a condensation mode at the initial phase transition. At the initial stage of the transitional regime, the droplet growth is affected by the thermal expansion of water along with the condensation of vapour on the droplet surface until the droplet surface temperature reaches the dew point temperature. Therefore, the droplet equivalent diameter is rapidly increasing in the beginning (Fig. 4, b, c and Fig. 5, c). At the time moment when the thermal expansion and evaporation effects equalizes the maximum peak forms in the droplet effective diameter variation graphs, from this point droplet starts to decrease consistently. Due to the expansion of the warming water and the surface condensation of vapour, the volume of the droplet in the additionally humidified air increases by about 2.7 percent (Fig. 7, curves 2 and 3).

The condition $\bar{T}_{r t}>1$ in low humidity air was not satisfied in the first, fourth and fifth experiments. Therefore, no condensation regime occurred during the initial phase 
transition. In the fourth and fifth cases, the condition $\bar{T}_{e}<1$ was still valid and the droplet initially cooled (Fig. 6 curves 5 and 6 ). As the equilibrium evaporation regime started from the beginning, the droplet began to shrink immediately (Fig. 5, a and b). In the first experiment $\bar{T}_{e}>1$ was still valid, so the droplet warmed up (Fig. 6, curve 1), but thermal expansion of water is quickly compensated by the water surface evaporation process. Therefore, the droplet volume increased only about 0.2 percent in the first experiment (Fig. 7 curve 1 ).

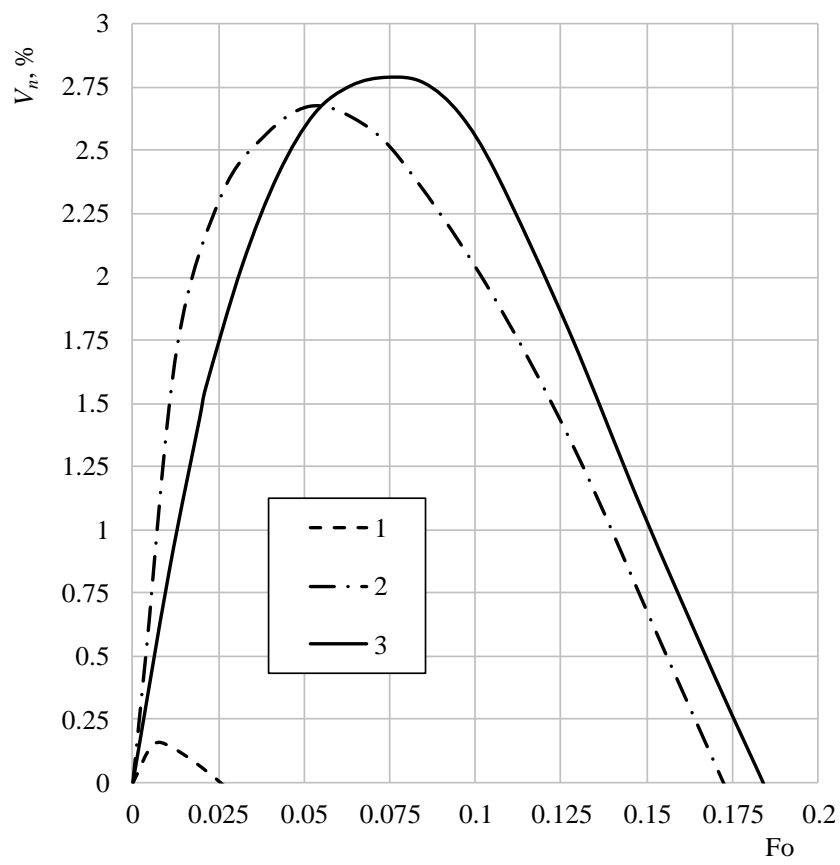

Fig. 7 The Influence of air flow parameters for the droplet growth at the initial point of the transitional phase change regime. The duration of the condensation regime $\tau_{c o}$, s: (1) 0 , (2) 0.16 , and (3) 0.92 ; The parameter $a_{0} / R_{0}^{2}:$ (1) 0.023059 , (2) 0.025764 , and (3) $0.021258 ; V_{n} \equiv\left(1-V / V_{0}\right) \cdot 100 \%$ and $V=4 \pi R^{3} / 3$; Case (1-3) are indicated in Fig. 3

In all experiments the water of the droplet was completely evaporated so that at the end of the equilibrium evaporation the equivalent diameter is equal the thermocouple beads diameter of $1.27 \mathrm{~mm}$ (Fig. 3). The evaporation time of the water was greatly influenced by the boundary conditions of the heat and mass transfer of the droplet and in the experiments performed it ranged from 50 to $230 \mathrm{sec}-$ onds (Fig. 3).

\section{Conclusions}

The results of the experimental investigation of the water droplets phase change in the additionally humidified gas flow confirmed the following:

1. The regularities of the water droplets phase changes in humid air flow is well illustrated by experimental diagrams of their diameter changes. In order to determine their specificity, a complex analysis of the phase transition modes of the droplet and the change in the thermal state of the droplet is required.

2. Phase transition processes on the surface of water are influenced by the droplets heat and mass transfer boundary conditions. The most important parameters are the humidity and temperature of the air and the temperature of the sprayed water.

3. For the first time, the results of the experiment substantiate that not only change of water droplet thermal state can be qualitatively determined by $\bar{T}_{d p}=T_{d p} / T_{0}$ and $\bar{T}_{e}=T_{e} / T_{0}$ in humid gas. But also the tendencies of the droplet geometric dimension (diameter, surface area, volume) in the initial phase transition phase can be predicted. The droplets will initially be reduced through evaporation when $\bar{T}_{e}<1$, or for $\bar{T}_{e}>1$, water will expand owing to thermal expansion, and the growth will be further stimulated by condensing the vapour when $\bar{T}_{r t}>1$.

4. According to the results of the experiment it can be stated that in the technology of heat recovery from the biofuel flue gas, the evaporation time of the droplets can vary up to 5 times depending on the conditions of water injection.

\section{References}

1. Rotunno, P.; Lanzini, A.; Leone, P. 2017. Energy and economic analysis of a water scrubbing based biogas upgrading process for biomethane injection into the gas grid or use as transportation fuel, Renewable Energy 102: 417-432.

https://doi.org/10.1016/j.ijhydene.2019.04.208.

2. Yu Lu; et al. 2019. Predicting the fracture initiation pressure for perforated water injection wells in fossil energy development, International Journal of Hydrogen Energy 44: 16257-16270.

https://doi.org/10.1016/j.ijhydene.2019.04.208.

3. Jacob, M.; et al. 2012. Removed: seawater treatment using UF and NF membrane processes for well water injection in the oil \& gas industry, Procedia Engineering 44: 2124-2136. https://doi.org/10.1016/j.proeng.2012.08.345.

4. Tarek Beji; Setareh Ebrahim Zadeh; Georgios Maragkos; Bart Merci. 2017. Influence of the particle injection rate, droplet size distribution and volume flux angular distribution on the results and computational time of water spray CFD simulations, Fire Safety Journal 91: 586-595. https://doi.org/10.1016/j.firesaf.2017.03.040.

5. Grout, S.; Blaisot, J. B.; Pajot, K.; Osbat, G. 2013. Experimental investigation on the injection of an ureawater solution in hot air stream for the SCR application: Evaporation and spray/wall interaction, Fuel 106: 166177.

https://doi.org/10.1016/j.fuel.2012.09.022.

6. Cheng Wei-min; et all. 2012. Research and practice on fluctuation water injection technology at low permeability coal seam, Safety Science 50: 851-856. https://doi.org/10.1016/j.ssci.2011.08.021.

7. Vershinina, K. Y.; Egorov, R. I.; Strizhak, P. A. 2016. A review of water injection applied on the internal combustion engine, Applied Thermal Engineering 107: 10-20.

https://doi.org/10.1016/j.applthermaleng.2016.06.156. 
8. Sipeng Zhu; et. al. 2019. A review of water injection applied on the internal combustion engine, Energy Conversion and Management 184: 139-158. https://doi.org/10.1016/j.enconman.2019.01.042.

9. Per Johan Brandvik; Chris Storey; Emlyn John Davies; Frode Leirvik. 2019. Quantification of oil droplets under high pressure laboratory experiments simulating deep water oil releases and subsea dispersants injection (SSDI), Marine Pollution Bulletin 138: $520-525$. https://doi.org/10.1016/j.marpolbul.2018.11.020.

10. Ramanauskas, V.; Puida, E.; Miliauskas, G.; Paukštaitis, L. 2019. Experimental Investigation of Water Droplet Heating in Humidified Air Flow, Mechanika 25(6): 434-441. https://doi.org/10.1016/j.marpolbul.2018.11.020.

11. Sazhin, S. S. 2006. Advanced models of fuel droplet heating and evaporation, Progress in Energy and Combustion Science 32: 162-214.

https://doi.org/10.1016/j.pecs.2005.11.001.

12. Mezhericher, M.; Levy, A.; Borde, I. 2010. Spray drying modelling based on advanced droplet drying kinetics, Chemical Engineering and Processing: Process Intensification 49: 1205-1213. https://doi.org/10.1016/j.cep.2010.19.002.

13. Beji, T.; Thielens, M.; Merci, B. 2019. Assessment of heating and evaporation modelling based on single suspended water droplet experiments, Fire Safety Journal 106: 124-135. https://doi.org/10.1016/j.firesaf.2019.04.012.

14. Wang, F.; et al. 2017. A new stationary droplet evaporation model and its validation, Chinese Journal of Aeronautics 30: 1107-1414. https://doi.org/10.1016/j.cja.2017.06.012.

15. Wu, Y.; Zhang, X.; Zhang, X. 2016. Simplified analysis of heat and mass transfer model in droplet evaporation process, Applied Thermal Engineering 99: 938-943.

https://doi.org/10.1016/j.cja.2017.06.012.

16. Fuks, N. A. 1959. Evaporation and Droplet Growth in Gaseous Media, London, Pergamum Press: 311.

17. Fujita, A.; Kurose, R.; Komori, S. 2010. Experimental study on effect of relative humidity on heat transfer of an evaporating water droplet in air flow, International Journal of Multiphase Flow 36: 244-247. https://doi.org/10.1016/j.ijmultiphaseflow.2009.10.004.

18. Vysokomornaya, V.; Kuznetsov, V.; Strizhak, P. A. 2014. Experimental investigation of atomized water droplet initial parameters influences on evaporation intensity in flaming combustion zone, Fire Safety Journal 70: 61-70.

https://doi.org/10.1016/j.firesaf.2014.08.016.

19. Volkov, R. S.; Kuznetsov, G. V.; Strizhak, P. A. 2015. Experimental investigation of mixtures and foreign inclusions in water droplets influence on integral characteristics of their evaporation during motion through high-temperature gas area, International Journal of Thermal Sciences 88: 193-200. https://doi.org/10.1016/j.ijthermalsci.2014.10.002.

20. Ruberto, S.; Reutzsch, J.; Weigand, B. 2016. Experimental investigation of the evaporation rate of supercooled water droplets at constant temperature and varying relative humidity, International Communications in Heat and Mass Transfer 77: 190-194. https://doi.org/10.1016/j.icheatmasstransfer.2016.08.005.

21. Strizhak, P. A.; Volkov, R. S.; Castanet, G.; Lemoine, F.; Rybdylova, O.; Sazhin, S. S. 2018. Heating and evaporation of suspended water droplets: Experimental studies and modelling, International Journal of Heat and Mass Transfer 127: 92-106.

https://doi.org/10.1016/j.ijheatmasstransfer.2018.06.103.

22. Yu, Y. S.; Wang, Z.; Zhao, Y. P. 2012. Experimental and theoretical investigations of evaporation of sessile water droplet on hydrophobic surfaces, Journal of Colloid and Interface Science 365: 254-259. https://doi.org/10.1016/j.jcis.2011.09.007.

23. Kumar, M.; Bhardwaj, R. 2018. A combined computational and experimental investigation on evaporation of a sessile water droplet on a heated hydrophilic substrate, International Journal of Heat and Mass Transfer 122: $1223-1238$.

https://doi.org/10.1016/j.ijheatmasstransfer.2018.02.065.

24. Zhanga, X.; Liub, X.; Wua, X.; Minb, J. 2018. Experimental investigation and statistical analysis of icing nucleation characteristics of sessile water droplets, Experimental Thermal and Fluid Science 99: 26-34. https://doi.org/10.1016/j.expthermflusci.2018.07.027.

25. Strub, M.; Jabbour, O.; Strub, F.; Bedecarrats, J. P. 2003. Experimental study and modelling of the crystallization of a water droplet, International Journal of Refrigeration 26: 59-68. https://doi.org/10.1016/S0140-7007(02)00021-X.

26. Yuntao Pan, Kewei Shi, Xili Duan, Greg F. Naterer, 2019. Experimental investigation of water droplet impact and freezing on micropatterned stainless steel surfaces with varying wettabilities, International Journal of Heat and Mass Transfer 129: 953-964.

27. https://doi.org/10.1016/j.ijheatmasstransfer.2018.10.032

28. Zhang, H.; Jin, Z.; Jiao, M.; Yang, Z. 2018. Experimental investigation of the impact and freezing processes of a water droplet on different cold concave surfaces, International Journal of Thermal Sciences 132: 498-508. https://doi.org/10.1016/j.ijthermalsci.2018.06.032.

29. Chaudhary G.; Li, R. 2014. Freezing of water droplets on solid surfaces: An experimental and numerical study, Experimental Thermal and Fluid Science 57: 86-93. https://doi.org/10.1016/j.expthermflusci.2014.04.007.

30. Hindmarsh, J. P.; Russell, A. B.; Chen, X. D. 2003. Experimental and numerical analysis of the temperature transition of a suspended freezing water droplet, International Journal of Heat and Mass Transfer 46: 11991213. https://doi.org/10.1016/S0017-9310(02)00399-X.

31. Yun-Feng Han; Ning-De Jin; Lu-Sheng Zhai; YingYu Ren, 2018. Experimental study of interaction between liquid droplets in oil-in-water emulsions using multivariate time series analysis, Chemical Engineering Science 192: 526-540.

https://doi.org/10.1016/j.ces.2018.08.001.

32. Shengxiang Deng; Jiemin Zhou. 2011. An experimental study of the effect of water content on combustion of coal tar/water emulsion droplets, Energy 36: 6130-6137. 
https://doi.org/10.1016/j.energy.2011.07.052.

33. Rene Ocampo-Barrera; Rafael Villasenor. 2001. An experimental study of the effect of water content on combustion of heavy fuel oil/water emulsion droplets, Combustion and flame 126: 1845-1855. https://doi.org/10.1016/S0010-2180(01)00295-4.

34. Ivanov, V. M.; Smirnova, E. V. 1962. Experimental research of liquid droplets evaporation velocity in nonmoving high temperature environment, Tr. IGI 19: 4658.

35. Longfei Chen; Zhixin Liu; Yuzhen Lin; Chi Zhang, 2016. Different spray droplet evaporation models for non-ideal multi-component fuels with experimental validation, International Journal of Heat and Mass Transfer, 94: 292-300.

https://doi.org/10.1016/j.ijheatmasstransfer.2015.11.017.

36. Kai Han; Bo Yang; Changlu Zhao; Geng Fu; Xiaokang Ma; Guoqian Song. 2016. Experimental study on evaporation characteristics of ethanol-diesel blend fuel droplet, Experimental Thermal and Fluid Science 70: 26-34.

https://doi.org/10.1016/j.expthermflusci.2015.10.001.

37. Cameron Verwey; Madjid Birouk, 2018. Experimental investigation of the effect of natural convection on the evaporation characteristics of small fuel droplets at moderately elevated temperature and pressure, International Journal of Heat and Mass Transfer 118: 10461055.

https://doi.org/10.1016/j.ijheatmasstransfer.2017.11.038.

38. Jigang Wang; Xiaorong Wang; Hao Chen; Zhangliang Jin; Kai Xiang, 2018. Experimental study on puffing and evaporation characteristics of jatropha straight vegetable oil (SVO) droplets, International Journal of Heat and Mass Transfer 119: 392-399.

https://doi.org/10.1016/j.ijheatmasstransfer.2017.11.130.

39. Ping Yi; Wuqiang Long; Liyan Feng; Weiyao Wang; Chao Liu. 2016. An experimental and numerical study of the evaporation and pyrolysis characteristics of lubricating oil droplets in the natural gas engine conditions, International Journal of Heat and Mass Transfer 103: 646-660.

https://doi.org/10.1016/j.ijheatmasstransfer.2016.07.084.

40. Belal Ali Al Zaitone; Cameron Tropea. 2011. Evaporation of pure liquid droplets: Comparison of droplet evaporation in an acoustic field versus glass-filament, Chemical Engineering Science 66: 3914-3921. https://doi.org/10.1016/j.ces.2011.05.011.

41. Kai Han; Bo Pang; Xiaokang Ma; Hao Chen; Guoqian Song; Zhaojing Ni. 2017. An experimental study of the burning characteristics of acetone-butanol-ethanol and diesel blend droplets, Energy 139: 853-861. https://doi.org/10.1016/j.energy.2017.08.037.

42. Li Genbao; Cao Jianming; Li Minglong; Quan Yuhua; Chen Zhaoyang. 2012. Experimental study on the size distribution characteristics of spray droplets of DME/diesel blended fuels, Fuel Processing Technology 104: 352-355. https://doi.org/10.1016/j.fuproc.2012.06.008.

43. Shams, Z.; Moghiman, M. 2017. An experimental investigation of ignition probability of diesel fuel droplets with metal oxide nanoparticles, Thermochimica Acta 657: 79-85.

https://doi.org/10.1016/j.tca.2017.09.007.

44. More Manjunath; Vasudevan Raghavan; Pramod S. Mehta. 2015. Vaporization characteristics of suspended droplets of biodiesel fuels of Indian origin and their diesel blends - An experimental study, International Journal of Heat and Mass Transfer 88: 28-41. https://doi.org/10.1016/j.ijheatmasstransfer.2015.04.052.

45. Dali Yang; Zhixun Xia; Liya Huang; Likun Ma; Yunchao Feng; Yunlei Xiao. 2018. Experimental study on the evaporation characteristics of the kerosene gel droplet, Experimental Thermal and Fluid Science 93: 171-177. https://doi.org/10.1016/j.expthermflusci.2017.12.031.

46. Burkert, A.; Paa, W. 2016. Ignition delay times of single kerosene droplets based on formaldehyde LIF detection, Fuel 167: 271-279

https://doi.org/10.1016/j.fuel.2015.11.051.

47. Irfan Javed; Seung Wook Baek; Khalid Waheed. 2014. Effects of dense concentrations of aluminium nanoparticles on the evaporation behaviour of kerosene droplet at elevated temperatures: The phenomenon of microexplosion, Experimental Thermal and Fluid Science 56: 33-44.

https://doi.org/10.1016/j.expthermflusci.2013.11.006.

48. Sazhin, S. S.; et al. 2011. Multi-component droplet heating and evaporation: Numerical simulation versus experimental data, International Journal of Thermal Sciences: 50: 1164-1180.

https://doi.org/10.1016/j.ijthermalsci.2011.02.020.

49. Abramzon, B.; Sirignano, W. A. 1989. Enhancement of water droplet evaporation by radiation absorption B. Abramzon, W. A Droplet vaporization model for spray combustion calculations, International Journal of Heat and Mass Transfer 32: 1605-1618. https://doi.org/10.1016/0017-9310(89)90043-4.

50. Tseng, C. C.; Viskanta, R. 2006. Enhancement of water droplet evaporation by radiation absorption, Fire Safety Journal 41: 236-247. https://doi.org/10.1016/j.firesaf.2006.01.001.

51. Miliauskas, G.; Maziukiene, M.; Jouhara, H.; Poškas, R. 2019. Investigation of mass and heat transfer transitional processes of water droplets in wet gas flow in the framework of energy recovery technologies for biofuel combustion and flue gas removal, Energy 173: 740-754. https://doi.org/10.1016/j.energy.2019.02.101.

52. Fujita, A.; Kurose, R.; Komori, S. 2010. Experimental study on effect of relative humidity on heat transfer of an evaporating water droplet in air flow, International Journal of Multiphase Flow 36: 244-247. https://doi.org/10.1016/j.ijmultiphaseflow.2019.10.004.

53. Ruberto, S.; Reutzsch, J.; Weigand, B. 2016. Experimental investigation of the evaporation rate of supercooled water droplets at constant temperature and varying relative humidity, International Journal of Multiphase Flow Communications in Heat and Mass Transfer 77: 190-194. https://doi.org/10.1016/j. icheatmasstransfer.2016.08.005.

54. Marques, O. 2011 Practical Image and Video Processing Using MATLAB. Wiley-IEEE Press: 451. 
https://onlinelibrary.wiley.com/doi/book/10.1002/9781118093467.

55. Miliauskas, G.; Maziukiene, M.; Ramanauskas, V.; Puida, E. 2017. The defining factors of the phase change cycle of water droplets that are warming in humid gas, International Journal of Heat and Mass Transfer 113: 683-703.

https://doi.org/10.1016/j.ijheatmasstransfer2017.05.129.
V. Ramanauskas, L. Paukštaitis, G. Miliauskas, E. Puida

EXPERIMENTAL INVESTIGATION OF WATER DROPLET PHASE CHANGE IN HUMIDIFIED AIR FLOW

S u m m a r y

An experimental research method and an analysis of the results of a water droplet phase change in the additionally humidified air flow are presented. The diagrams of variation of the equivalent diameter of convectively heated water droplets are presented and analysed. The influence of initial water temperature and additionally humidifying air flow on the phase change of a droplet in transient regime is experimentally substantiated.

Keywords: air flow, additionally humidifying, water droplets, phase change, experimental investigation.

Received October 25, 2019

Accepted June 02, 2020 